\title{
Analysis of Partial Power DC-DC Converters for Two-Stage Photovoltaic Systems
}

\author{
Jaime W. Zapata๑, Member, IEEE, Samir Kouro® , Senior Member, IEEE, Gonzalo Carrasco, \\ Hugues Renaudineau $₫$, Member, IEEE, and Thierry A. Meynard, Fellow, IEEE
}

\begin{abstract}
Two-stage photovoltaic (PV) configurations have become increasingly popular due to the decoupling between the inverter dc-link voltage and the PV voltage, adding flexibility to extend the maximum power point tracking range. However, the additional dcdc converter increases the power converter losses. The concept of partial power converters (PPCs), which reduce the amount of power handled by the dc stage, can mitigate this effect. However, the type of topology, its power and voltage rating, efficiency, and an operating range can vary significantly depending on the function (boosting or reducing voltage) and type of PV application and scale (micro-, string-, or multisting inverter). This paper analyzes the possible configuration of connections of PPC depending on the application and scale of the PV system and introduces a new buck-type PPC. Three solutions for practical PV systems are further elaborated, including experimental validation. Results show that the PPC concept greatly improves the overall PV system efficiency with the added benefit that the dc-dc stage power ratings achieved are only a fraction of the PV system, reducing size and cost of the power converter without affecting the system performance.
\end{abstract}

Index Terms-DC-DC converters, microinverter, string inverter, partial power converters (PPCs), photovoltaic (PV) energy.

I. INTRODUCTION WO-STAGE power conversion systems can increase the maximum power $\mathbf{T}$ Tpoint tracking (MPPT) range in grid-connected photovoltaic (PV) energy conversion systems. This is possible due to the decoupling between the inverter dc-link voltage and the PV voltage. They have become increasingly popular for several PV applications ranging from small to large scale. In small-scale PV applications, such as microinverters, the dc-dc stage is almost mandatory in order to elevate the voltage of a single PV module (of $\approx 30 \mathrm{~V}$ ) to the required dc-link voltage for grid connection [1].

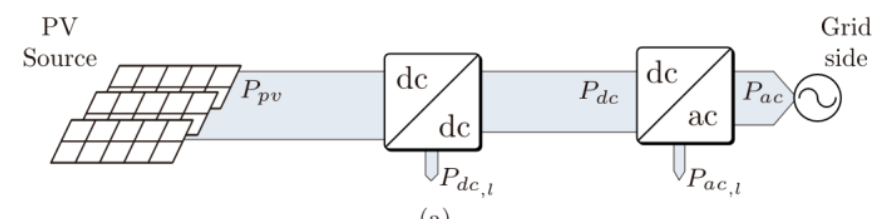

(a)

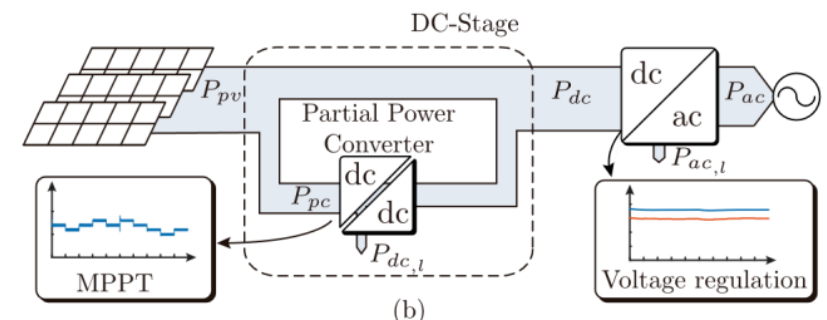

(b)

Fig. 1. Power flow of a two-stage PV system (a) working with an FPC and (b) working with a PPC.

Even large-scale PV plants favor now two-stage string and multistring inverters over single-stage central inverters, not only to reduce the effects of partial shading [2], but also to mitigate the effect of temperature fluctuations that produce a wider voltage operating range (particularly in desert climates with high night/day temperature gradient).

On the other hand, the additional conversion stage leads to an increase of the component count, cost, and size, but more importantly, it adds more converter losses to the system. Both converter stages, the $\mathrm{dc}-\mathrm{dc}$ and the $\mathrm{dc}-\mathrm{ac}$, process all the power flowing from the PV system to the grid, which is known as the full power converter (FPC), as shown in Fig. 1(a). The power losses of each stage, $P_{\mathrm{dc}, l}$ and $P_{\mathrm{ac}, l}$, depend on the converter efficiency and the amount of power handled by each converter.

The partial power converter (PPC) concept has been around in other applications, such as wind turbines, by using a doubly fed induction generator with an indirect four quadrant ac-dc-ac converter connected between the rotor windings [3] and the grid, and an additional direct grid connection to the stator. In this case, the converter is only rated at $30 \%$ of the wind turbine power; yet it provides enough control range to perform variable speed operation and MPPT. The PPC concept oriented to PV systems was introduced in [2], in order to reduce the power losses inherent in two-stage configurations. Nevertheless, despite the presented classification of dc-dc converters in this reference, the PPC configurations 


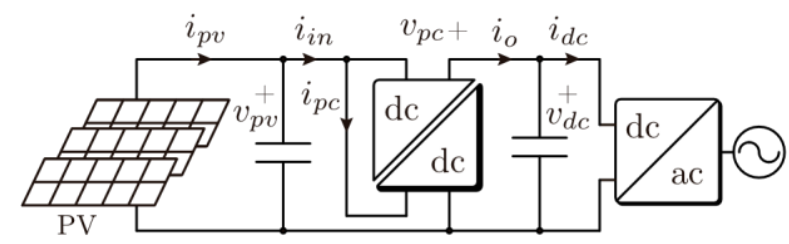

Source

(a)

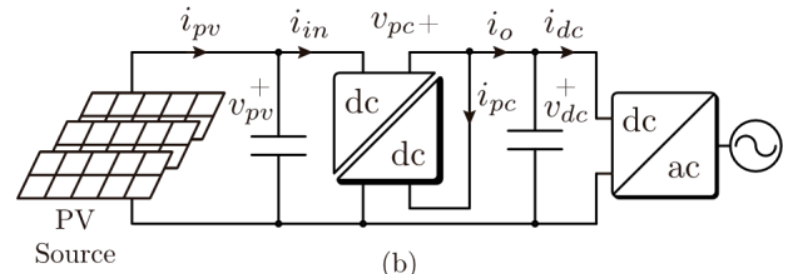

(b)

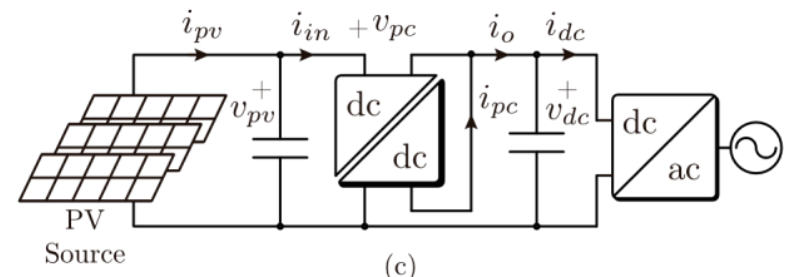

(c)

Fig. 2. PPC configurations for two-stage PV systems (a) step-up, input side connected to the PV system (step-up I), (b) step-up, input side connected to the dc link (step-up II), and (c) step-down, input side connected to the PV system (step-down).

are not the focus of analysis and evaluation in their work. The operation principle of a PPC is based on the power biasing, establishing a series path between the input and output sides. It has received several names over the years, including partial capacity converter, partial power processing converters, series voltage compensation, and PV balancers. In essence, the operating principle is to connect a series voltage between the PV system and the dc link of the inverter. Since this voltage is usually smaller than the other two, it will process less power. In addition, the PPC is used to control indirectly the PV system output voltage to ensure MPPT, by controlling the series-injected voltage. Hence, it is not really a voltage balancing converter (there is no actual voltage unbalance), and therefore, PPC will be used as nomenclature in this paper.

The power flow path of the PPC in a two-stage PV system is shown in Fig. 1(b). In this case, only the portion of power handled by the partial dc-dc converter can lead to converter losses $P_{\mathrm{dc}, l}$, which will be inherently lower than with FPC. In order to connect an independently controlled dc voltage between the PV system and the dc link and to create the power bypass path, high-frequency isolated dc-dc topologies can be used. The input power for this independent voltage can come either from the PV side or the dclink side, as shown in the possible connections shown in Fig. 2.

This paper explores three dimensions of the PPC: the configuration, the topology, and the PV application. The configuration is related to how the series voltage is connected, whether it is sourced from the PV side or from the dc-link side, also if it has a stepup or step-down operation. The topology has direct relation with the type of dc-dc power circuit (flyback, full-bridge, and so on). The PV application is related to the use and scale of the PV system, namely microinverter, small string with step-up requirement, and large string with step-down function. All these dimensions have an impact on the converter ratings and efficiency.

The PPC configuration based on the connection shown in Fig. 2(a), where a step-up operation is obtained, was introduced for a spacecraft application in order to improve the performance compared with the traditional boost converter [4]. Other applications based on the same series connection are found in [5] and [6], where a 25-kW prototype was developed. The topology used for the experiment was four full-bridge converters connected in series, designed to handle $30.7 \%$ of the rated power and achieving an efficiency around $96 \%$ working at $33 \mathrm{kHz}$. In [7], a buck-boost PPC is proposed for a 30-W prototype, using a flyback converter. However, for a PV application, the solution is not suitable because of the reverse current obtained when the converter works in buck operation. In [8]-[11], the focus is on the use of PPC for microinverter configurations. They present an improvement in the conversion efficiency, which is commonly a problem in microinverters due to the high-voltage elevation required for the grid connection.

It is also possible to achieve a step-up operation using the connection shown in Fig. 2(b). In [12], a flyback converter was used reaching an experimental efficiency between $89 \%$ and $97 \%$. The focus of [12] is to decrease the size of the PPC by reducing its rating and to serve as a replacement of the junction box in PV modules. However, the configuration has limitations on the voltage elevation as is explained in [13], where the maximum gain must be less than the double of the input voltage. Another application is found in [14], where an isolated Cuk topology is implemented into a powered' electric aircraft. The converter is rated for $26 \%$ of the $2.7-\mathrm{kW}$ generated power, and it achieves an experimental efficiency above $95 \%$.

There are different PPC configurations that can be used depending on the two-stage PV architecture. Even though PPCs have been presented in the past, they have been focused on two of them, only for voltage boost operation. The main contributions of this paper are that the PPC concept is now completed by including the buck operation for larger strings, as shown in Fig. 2(c). 
Note that, today, new PV strings can reach up to $1500 \mathrm{~V}$ by using the new higher isolation modules [15], making larger strings a reality and increasing the need of buck dc-dc stages to properly connect to grid-voltage levels. Moreover, this paper introduces an analysis to select a suitable PPC configuration depending on the PV application, either for a microinverter or a string inverter (with small or large string). The selection is based on the voltage regulation ratio, the level of partiality achieved, and the isolated topologies used to build the PPC. Three experimental converters are developed in order to test each configuration and to show the improvements in the conversion efficiency.

\section{PARTIAL POWER CONVERTERS FOR PV SYSTEMS}

Depending on the scale of the PV system, the input source can be a single module, a string, or an array. The amount of PV modules in series forming the string will define the operating voltage range. Hence, the dc-dc converter must control the input voltage $v_{\mathrm{pv}}$ to the desired MPPT voltage reference. In addition, the $\mathrm{dc}-\mathrm{dc}$ converter performs the conversion between the PV voltage and the inverter dc-link voltage $v_{\mathrm{dc}}$. In a conventional PV system, usually, the dc-link voltage is controlled by the gridtied inverter to a value higher than the peak voltage of the grid. Therefore, depending on the PV source and the inverter requirements, the PV voltage must be either elevated or reduced by the dc-dc converter. Since all the power is processed by the dc-dc stage, the total system losses are higher compared with a single-stage PV system. However, the total efficiency of a twostage PV system can be improved if the converter processes a fraction of the power to perform the function of the dc stage. When the voltage compensated by the dc stage or its current is smaller compared with the input source voltage or current, the power driven by the $\mathrm{dc}-\mathrm{dc}$ converter is also a fraction of the system power and, hence, the name of PPC.

A parameter to describe the amount of power processed by the converter is defined as

$$
K_{\mathrm{pr}}=-\quad \text { (1) }{ }_{P \mathrm{pv}}^{P \mathrm{pc}}
$$

where $P_{\mathrm{pc}}$ and $P_{\mathrm{pv}}$ are the power processed by the converter and the power delivered by the PV system, respectively. Thus, for the converter to be operating as a PPC, it must be operating with a partial power ratio below unity $K_{\mathrm{pr}}<1$.

The dc-dc converter must obtain the power from the PV system side or the dc-link side, and because of the connection required for the compensation voltage to the same PV or the dc-link side, the PPC configurations are made with high-frequency isolated $\mathrm{dc}-\mathrm{dc}$ topologies, in order to avoid a short circuit. It is important to note that this high-frequency transformer will not provide effective galvanic isolation for the PV system. This might be seen as a drawback, but considering that the power rating of the converter is much lower than the total power, this is not a significant issue. Furthermore, the grounding of the PV system can be achieved by the proper selection of the inverter stage and modulation, as with traditional transformerless PV inverters [1].

The polarity of the voltage generated by the PPC is given by the secondary circuit connection of the transformer. This connection can be implemented either: 1) adding voltage in the same polarity to the PV system to reach the dc-link voltage (boost function); or 2) subtracting voltage to the PV system providing a buck effect. The first case is useful for microinverters or string inverters with small string voltage. The second connection is useful for string inverters with large string voltages. For both connections, the operating principles of MPPT regulation are shown in Fig. 3. Note that the amplitude of the PPC voltage $v_{\mathrm{pc}}$ can be regulated to adjust the PV system voltage $v_{\mathrm{pv}}$, since the dc-link voltage $v_{\mathrm{dc}}$ will remain fixed by the inverter control.

As is known, power optimizers are developed as an alternative to maximize the energy harvest from the PV system, using a dedicated dc-dc converter performing MPPT on each individual PV module. Due to high installation costs, they are commonly used in small-scale applications, such as rooftop systems [1]. In contrast with traditional microinverters orstring inverters, the output terminals of the power optimizers are connected between them to form a string before they are connected to the grid-tied inverter [16]. For this reason, PPC power optimizers will have different voltages and partial power operating conditions than the configurations analyzed in this paper. Therefore, the proposed analysis and conclusions regarding efficiency do not necessarily apply when PPC is used working as power optimizers and is a matter of future research

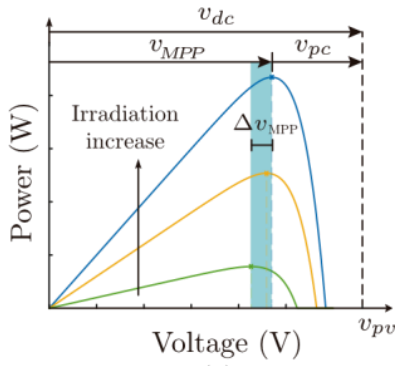

(a)

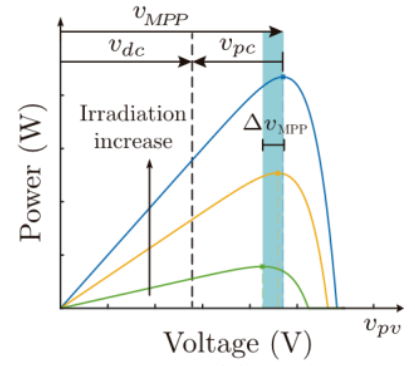

(b)

Fig. 3. Operation in a PV system. (a) Positive series connections (step-up operation). (b) Negative series connection (step-down operation). 


\section{TOPOLOGIES AND OPERATING FEATURES OF THE PPC}

In this paper, flyback and full-bridge high-frequency isolated dc-dc converter topologies will be considered for the different configurations, depending how they best fit according to the PV application. The voltage gain $G_{\nu}=v_{\mathrm{dc}} / v_{\mathrm{pv}}$ in continuous conduction mode for both topologies working as FPC are given by nd

$$
\left.\begin{array}{ll}
v_{-} \text {Fly }= & -\quad G
\end{array}\right] \text { (2a) }
$$

where $d$ represents the $n_{2}(2 \mathrm{~b})$ duty cycle and $n$ represents the turns ratio of the transformer between the low voltage side $n_{1}$ and the high voltage side $n_{2}$. Note that for the flyback, the voltage elevation can be achieved choosing a turns ratio greater than one or adjusting the duty cycle only. On the other hand, in the full-bridge, the voltage elevation is only achieved through the transformer. The gains in (2a) and (2b) are related not only to the converters considered in this paper, but they are also found in other traditional isolated dc-dc converters (forward, Cuk,' half-bridge, and so on) [17]. In order to derive the equations describing the PPCs, the step-up I PPC shown in Fig. 2(a) is considered as a case of study. In general terms, no matter the PPC configuration nor the isolated dc-dc topology, the voltage gain

$G_{v}$ of the dc stage is expressed as

$$
G_{v}=\longleftarrow \quad \text { (3) } \begin{aligned}
& V_{\mathrm{dc}} \\
& V_{\mathrm{pv}}
\end{aligned}
$$

Moreover, considering that the input and output capacitors losses are neglected, and including (3), the dc-stage conversion efficiency $\eta$ is expressed as

$$
\eta=G_{\nu} \longrightarrow
$$

OPERATION PARAMETERS

\begin{tabular}{lccc}
\hline \hline PPC configuration & $G_{v}$ Flyback & $G_{v}$ Full-bridge & $K_{p r}$ \\
\hline Step-up I & $\frac{1+d(n-1)}{1-d}$ & $1+n(1-d)$ & $1-\frac{\eta}{G_{v}}$ \\
Step-up II & $\frac{n(1-d)}{n(1-d)-d}$ & $\frac{n}{n-1+d}$ & $G_{v}-\eta$ \\
Step-down & $\frac{d n}{1+d(n-1)}$ & $\frac{n(1-d)}{n(1-d)+1}$ & $1-G_{v}$ \\
\hline \hline
\end{tabular}

By Kirchhoff laws and due to the PPC connection, the voltage and the current are expressed as

$$
\begin{gathered}
V_{\mathrm{dc}}=V_{\mathrm{pv}}+V_{\mathrm{pc}} \\
I_{\text {in }}=I \mathrm{pc}+I o .
\end{gathered}
$$

Then, in order to define the operation region of the PPC, the partial power ratio $K_{\mathrm{pr}}$ can be expressed in terms of the dc-stage efficiency and voltage gain as

$$
K_{\mathrm{pr}}=1-\ldots \quad \text { (7) } G_{v}
$$

To obtain the voltage gain expression, working with a flyback topology for the step-up I PPC configuration, the dc-dc converter voltage gain $G_{\mathrm{vc}}$ is obtained by

$$
G^{\mathrm{vc}}=\frac{V_{\mathrm{pc}}}{V_{\mathrm{pv}}} \quad \frac{n d}{1 d}=-
$$

Applying (5) in (8), the equation can be expressed as

$$
\begin{array}{cc}
\underline{V_{\mathrm{dc}}-V_{\mathrm{pv}}}=\frac{n d-}{V_{\mathrm{pv}}} & 1 d
\end{array} .
$$

Rearranging and simplifying the expression, and also considering (3), the global voltage gain can be calculated by

$$
1+d(n-1)
$$


The same analysis can be made for the different PPC configurations with another dc-dc topology. Table I presents the equations derived for the flyback- and full-bridge-based PPCs. Working as a PPC, the voltage gain $G_{v}$ and the partial power ratio $K_{\mathrm{pr}}$ change depending on the configuration. The operation curves of the PPC configurations, working with the flyback and full-bridge topologies, are summarized in Table II, where the region representing the partial power operation is highlighted by the shadowed area. The figures depicted in Table II show the following important features: the voltage gain $\left(G_{v}\right)$, the duty cycle $(d=[0-1])$, the range of partial power ratio $\left(K_{\mathrm{pr}}\right)$, and the turns ratio of the transformer $(n)$. As can be seen from the derived equations, the parameter $K_{\mathrm{pr}}$ only depends on the voltage gain and the PPC configuration regardless the dc-dc topology. On the other hand, the operation of a converter is limited by the range of the duty cycle $d=[0-1]$, which does depend on the dc-dc topology (fullbridge, flyback, and so on), the voltage gain, the transformer turns ratio, and the PPC configuration. It is explained in detail in Sections III-A and III-B.

\title{
A. Step-Up Partial Power Converters
}

Based on the configurations shown in Fig. 2(a) and (b), it is possible to perform a step-up operation. The main difference

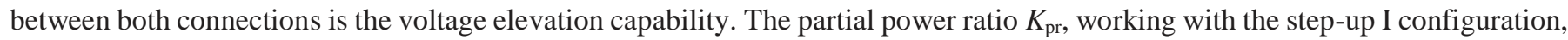
increases, while the voltage gain $G_{v}$ also increases, and the gain is theoretically not limited to a maximum value when the flyback topology is chosen. This feature makes it a suitable configuration for applications with a high voltage gain requirement. On the other hand, when the voltage gain is small (e.g., $G_{v}<2$ ), the duty cycle is limited within a small operation range, which depends on the topology and the transformer turns ratio $n$. It means that a high resolution in the control platform is needed to compensate the small variations. When the full-bridge topology is chosen, the transformer turns ratio limits the maximum voltage gain but the operation range of the duty cycle is higher compared with the flyback topology.

1) Microinverter Configuration: A typical PV application for this case is microinverters. These configurations require a high-voltage step-up ratio, since they are used for a single PV module ( $30 \mathrm{~V})$ [18]. Moreover, the nominal power for some commercial PV modules is around $300 \mathrm{~W}$. Therefore, the step-up PPC shown in Fig. 2(a) is the most suitable option for this application, since the partial power operation is not limited by the voltage gain. Regarding the topology selection, the traditional flyback converter is chosen not only due to its simple structure [see Fig. 4(a)], but also because its operation features. The same advantages of an interleaved operation with two dc converters can be obtained with a single PPC by choosing appropriate parameters [19]. This is further discussed in Section IV.

As an example, for a single PV module operating at $V_{\mathrm{pv}}=30 \mathrm{~V}$, with a single-phase inverter with a dc-link voltage of $V_{\mathrm{dc}}=180 \mathrm{~V}$, for a grid connection of $V_{g}=110 \mathrm{~V}_{\mathrm{rms}}$, based on Table II, a possible solution is to select a transformer with $n=5$ turn ratio in order to work with a duty cycle around $d=0.5$. This is usually chosen to reduce the magnetic losses [20].

In this case, the partial ratio will be around $K_{\mathrm{pr}} 83 \%$, which means that the converter power rating can be reduced to around $17 \%$.

2) String and Multistring Inverter Configuration: Traditionally, the two-stage string and multistring inverter configurations are used for small- and medium-scale PV applications, although they have been recently gaining more and more relevance in large power plants. Commonly used dc-dc converter topologies for these applications are based on high-frequency isolated fullbridge converters, in some cases operating as resonant converters. It is important to note that when working with full-bridge topologies, there is a circulating current produced by the stored energy in the magnetization inductance, which decreases the efficiency of the $\mathrm{dc}-\mathrm{dc}$ converter. This effect is mitigated with the PPC configurations, since the dc-dc converter is handling a small portion of the total power.

The possible solutions will depend on the voltage elevation requirement. If the output voltage to be reached is greater than the double of the input voltage, the only solution to be considered is the configuration shown in Fig. 2(a). In that case, the step-up I configuration using a full-bridge topology shows that the partial ratio $K_{\text {pr }}$ depends on the voltage gain and is limited by the transformer turns ratio. However, if the application works with an input value closer to the dc-link voltage, the turns ratio of the transformer will be closer to one, which will provide a wider range of operation for the duty cycle.

Considering a system working with a string of eight

PV modules at $V_{\mathrm{pv}}=240 \mathrm{~V}$ and a single-phase inverter

\author{
TABLE II
}

OPERATION OF PPCs FOR DIFFERENT TOPOLOGIES AND APPLICATIONS FOR PV SYSTEMS 


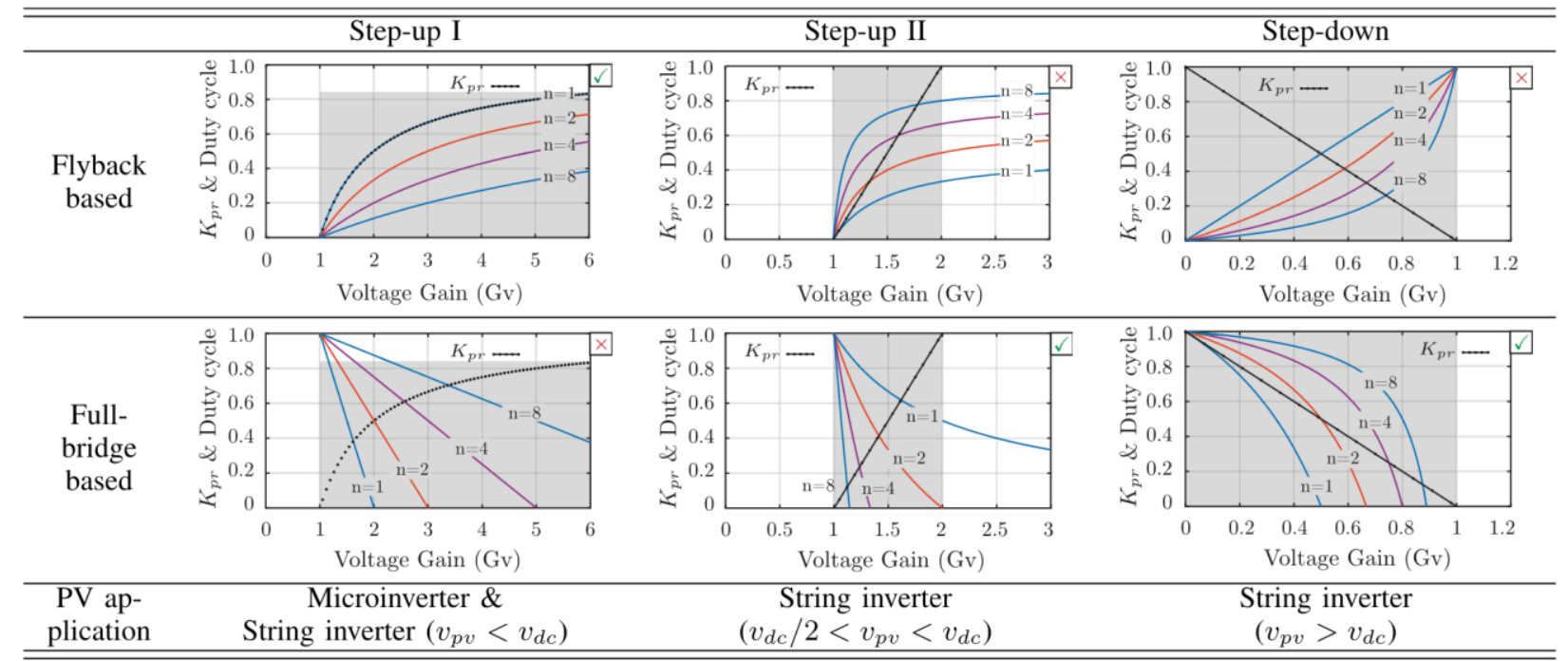

$\checkmark$ Are included in the analysis of the paper and experimental results due to their more practical interest for PV systems.

$\times$ Are the ones which are not evaluated experimentally due to their lack of practical interest for PV systems.

The shadowed area represents the region of partial power operation.

$V_{\mathrm{dc}}=360 \mathrm{~V}$ for a grid of $V_{g}=220 \mathrm{~V}_{\mathrm{rms}}$, the voltage gain is $G_{v}=1.5$. It is possible to see that the maximum duty cycle range is limited between $[0.5,1]$ using a transformer with $n=1$. The duty cycle resolution decreases becoming a limit for the controller and modulation when the turns ratio increases.

On the other hand, working with the configuration shown in Fig. 2(b), the step-up II configuration using a full-bridge topology is chosen, and the gain is limited to the double of the input voltage. However, if a string is large enough to work close to the dclink voltage, the converter can work with a different turns ratio and a wide resolution in the duty cycle. This configuration is evaluated in the experimental prototype, based on the circuit shown in Fig. 4(b).

\section{B. Step-Down Partial Power Converters}

Large-scale solar PV systems (e.g., in desert regions) with small or almost negligible partial shading have been favoring larger PV strings to increase the operating voltage and reduce dc conduction losses within the plant. Currently, the most widely available string voltages are designed for operation under 1000-V open-circuit voltage (800-900 V typically), due to the voltage isolation limits of the PV modules. However, due to benefits working with larger strings, the PV industry tends to increase the level of insulation from 1000 to $1500 \mathrm{~V}$ [15], while the inverter grid side voltage still remains usually at $690 \mathrm{~V}$. For single-stage PV systems, it will require the inverter to work with smaller duty cycles, to step down the voltage, forcing the converter to work in ratings where it is not very efficient. This has become a relevant issue in desert areas with large temperature fluctuations, with colder mornings and evenings, in which the PV string voltage is highest, forcing the converter to operate at much lower efficiencies than the ones offered in their data sheets. Furthermore, the semiconductors of the inverter must be rated to block at higher voltage levels. This is why two-stage solutions are becoming popular, in addition to better MPPT capability.

The step-down PPC is proposed in this paper and is based on the configuration connection shown in Fig. 2(c) to reduce the PV voltage to the dc-link voltage. The output voltage needed to perform grid connection is the difference between the input $v_{\text {pv }}$ and the converter $v_{\mathrm{pc}}$ voltages, as shown in Fig. 3(b). As shown in Table II, when the voltage gain $G_{v}$ is close to the unitary value of the converter, it works with a small partial power ratio $K_{\mathrm{pr}}$. This means that the components' power rating can be reduced and the conversion efficiency of the dc stage will increase.

The converter operating point depends on the topology, the turns ratio of the transformer, and the voltage gain. In this case, the topologies considered for the analysis are the flyback and full bridge. In small-scale applications, the flyback topology with a transformer turns ratio close to $n=1$ is a suitable solution, since the duty cycle resolution decreases when the turns ratio increases. This is directly related to the resolution in the control platform, which is needed to compensate the voltage variations.

On the other hand, the full-bridge topology is used for higher power ratings than the flyback. When using it as a step-down PPC, the voltage gain is limited by the transformer turns ratio. Considering a design where the maximum power processed by the converter will be $K_{\mathrm{pr}}<40 \%$ and based on Table II, the voltage gain range will be $G_{v}=[0.6-1]$. 


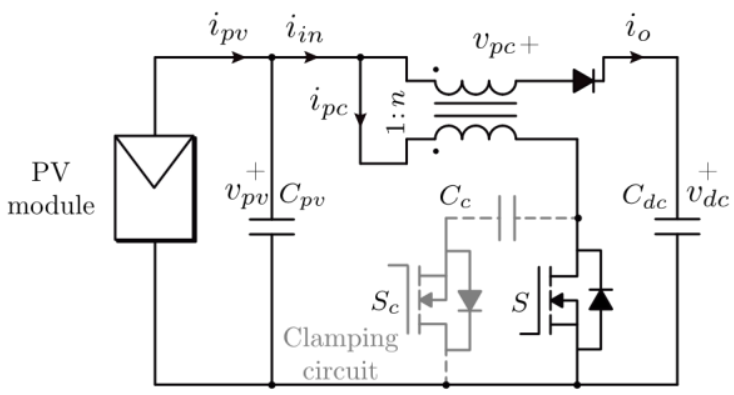

(a)

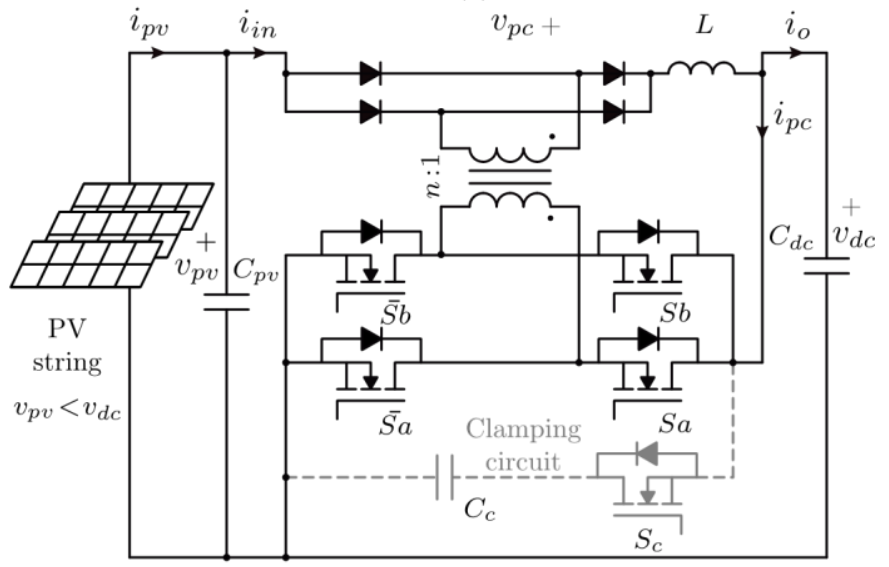

(b)

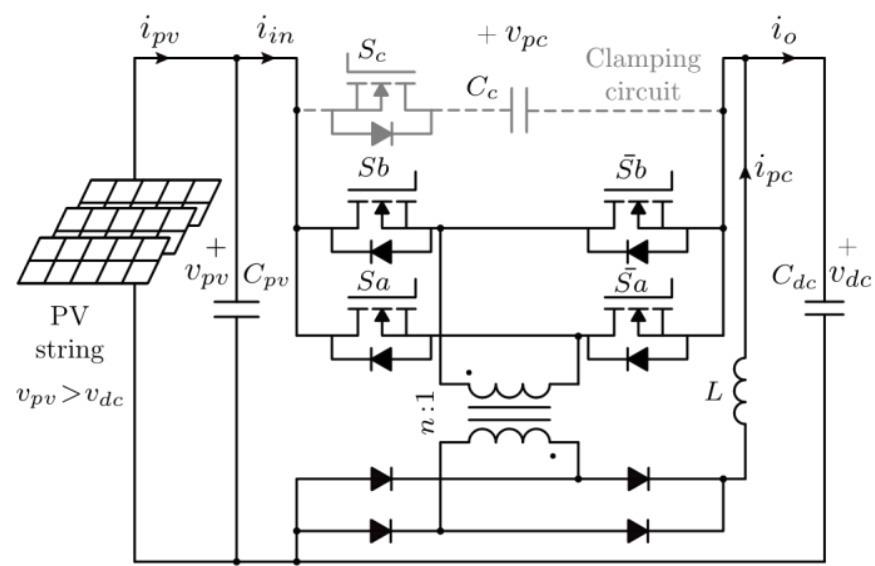

(c)

Fig. 4. Selected PPC configuration, topology, and PV application. (a) Step-up I PPC with flyback for microinverter. (b) Step-up II PPC with full bridge for string inverter. (c) Step-down PPC with full bridge for string inverter.

Moreover, as can be seen in the figure for the step-down full-

bridge-based PPC depicted in Table II, a higher transformer turns ratio allows a better performance in terms of duty cycle, and hence, the selected turns ratio is $n=8$. Based on the equation of the voltage gain for a step-down full-bridge-based PPC, described in Table I, it is possible to find the duty cycle range $d=[0-0.81]$. With this information, it is also possible to define the range of the voltage gain, which, in this case, is $G_{v}=[60 \%-89 \%]$.

As can be noted, the duty cycle range is wide enough to operate with the control platform available in the experimental test bench. Due to the selection criteria and the laboratory

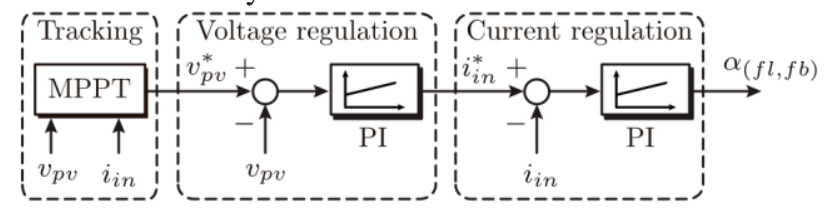

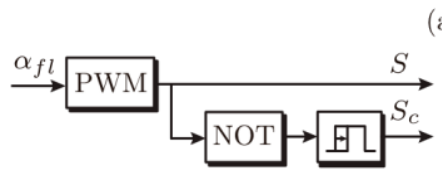

(b)

(a)

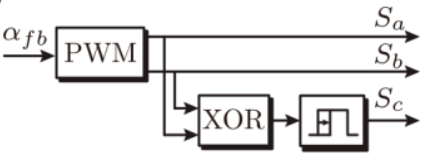

(c) 
Fig. 5. Control scheme implemented in the experimental test bench. (a) General control loops. (b) Gate signal generation for the flyback-based PPC. (c) Gate signal generation for the full-bridge-based PPC.

facilities, the configuration evaluated in the experimental prototype is based on the circuit shown in Fig. 4(c).

Because of the parasitic components of both, the HF transformer and MOSFETs, combined with the fast turn-ON time for the MOSFETs operation, the isolated full-bridge converter experiences a voltage overshoot and oscillations [21]. In the literature, it is possible to find solutions in order to overcome this effect, mitigating these overvoltages and at the same time increasing the converter efficiency [22]. One of them is the clamping circuit, which is implemented in this paper and shown in gray in Fig. 4(c).

\section{Control Scheme}

The control scheme implemented for the all the PPCs described previously is based on cascaded control loops working with linear PI controllers, as shown in Fig. 5(a). The external control loop includes the MPPT algorithm. For this purpose, the classical perturb and observe (P\&O) algorithm was implemented, due to its simple implementation and effective tracking of the MPP [23]. The PPCs are modeled through state variables, and they are used to find the parameters for the controllers. Due to paper length limitations, not all the models are included, but the methodology is the same for another PPC configurations. The control design of the step-down fullbridge-based PPC shown in Fig. 4(c) is derived in this section. The dynamic equation for the current in the inductance is derived as

$$
\begin{aligned}
& \left(v_{\mathrm{pv}}-v_{\mathrm{dc}}\right) n(1-d)-v_{L}-v_{\mathrm{dc}}=0 v_{L}=v_{\mathrm{pv}} n(1-d)-v_{\mathrm{dc}}(n(1-d)+1) d i_{L} \\
& -\quad\left(v_{\mathrm{pv}} n(1-d)-v_{\mathrm{dc}}(n(1-d)+1)\right) . \quad \text { (11) } d t L
\end{aligned}
$$

Moreover, the dynamic equation for the input voltage in the capacitor $C_{\mathrm{pv}}$ is derived as $i_{\mathrm{pv}}-i \mathrm{in}-i C_{\mathrm{pv}}=0 i C_{\mathrm{pv}}=i_{\mathrm{pv}}-i$ in

$$
\begin{array}{lllll}
d v_{\mathrm{pv}} & 1 & P \mathrm{pv} & P \mathrm{pv} \\
d t & - & - & - & -
\end{array}
$$

The selected variables of state are the PV voltage $v_{\mathrm{pv}}$ and the current through the inductor $i_{L}=i_{\mathrm{pc}}$. It is because the dominant dynamics are determined by: the input capacitor voltage, so that this is the responsible for changing the voltage when the MPPT algorithm is made, and the current through the inductor allows the direct control of amount of power taken from the PV system. In order to express in variables of state, it is possible to consider the following representations: $x=x x 12==i v L \mathrm{pv} u p==d v \mathrm{dc}$

$$
\begin{aligned}
& 1 \\
& -
\end{aligned}
$$

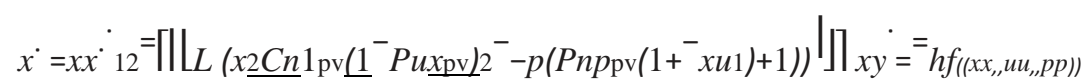

$$
\begin{aligned}
& 1 \\
& \left.\dot{x}=\left[\left[\mid{ }^{1} f L 2=C_{2} 1_{\mathrm{pv}}-P u x_{\mathrm{pv} 2}\right)--p P(n p \mathrm{pv}(1+-x u 1)+1)\right)\right]|| .(13) f=-(x n(1
\end{aligned}
$$

The equation shown in (13) represents a nonlinear model, because there are multiplications between the inputs with the state variables. Therefore, the following analysis is performed to obtain a linear model

$$
\begin{aligned}
& x=\mathbf{A} x+\mathbf{B} u+\mathbf{E} p \\
& =\mathbf{C} \Delta x+\mathbf{D} \Delta u+ \\
& \text { 目 } \partial f_{1} \quad \partial f_{1} \mid \quad 0
\end{aligned}
$$

$y$

$$
\begin{aligned}
& \mathbf{F} p \\
& 0 \quad \frac{1}{L} n\left(1-\left.\frac{}{\partial x_{1}} \quad \overline{\partial x_{2}}\right|_{x=x} \quad \mid u 0\right) \mid \\
& \mathbf{A}=\left|\begin{array}{ll}
\underline{\partial f_{2}} & \underline{\partial f_{2}}
\end{array}\right| \begin{array}{c}
1 \\
u=u_{0}
\end{array}=1 \quad-P_{\mathrm{pv}} \\
& \left\lfloor\partial x 11 \partial x_{2}\right\rfloor_{00} p \quad p_{0} \quad\left\lfloor\overline{C_{\mathrm{pv}}}=\quad C_{\mathrm{pv} x 202} \|\right.
\end{aligned}
$$




$$
\begin{aligned}
& -\frac{-}{L}\left(x_{20}-\right. \\
& \left\lceil-\left.\partial f\right|^{0} n\right. \\
& \left.\mathbf{B}=\stackrel{u}{\partial f_{2}}\left\|_{\partial}\right\|_{x=u x} \quad=\quad p 0\right) \quad \partial u \quad p=p^{0}
\end{aligned}
$$

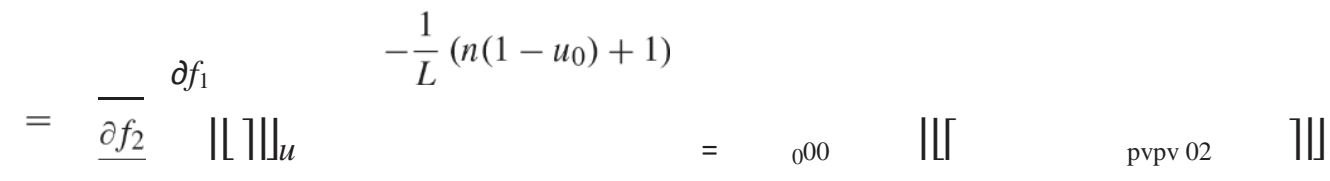

$$
\begin{aligned}
& \mathbf{E} \quad\lceil\partial p \quad u x==u p=\quad C P p \\
& \partial p \quad p=
\end{aligned}
$$

The obtained matrix is possible to solve the linearized equa- tions around an operating point as shown in the following:

$$
\begin{aligned}
& s \cdot x=\mathbf{A} x+\mathbf{B} u \\
& y=\mathbf{C} x \\
& y \begin{array}{l}
1 \\
u
\end{array}=\mathbf{C} \cdot(s \mathbf{I}-\mathbf{A})^{-} \cdot \mathbf{B} .
\end{aligned}
$$

This model is given for a generic variable, and hence, it can be expressed for current and the duty cycle by

$$
C y=[=1 i L 0] .
$$

On the other hand, in can be expressed for input voltage and the duty cycle by

$$
C y=\left[=0 v_{\mathrm{pv}} 1\right] .
$$

With this information, it is possible to obtain the required models for designing the controllers. As can be seen in Fig. 5, the controllers are based on a cascaded control loop. The inner

loop controls the current, and the outer loop controls the input voltage. It is because the dynamic of the current is faster than the voltage dynamic. As it is known, the voltage reference changes depending on the MPPT algorithm, and this time takes commonly some seconds $t \approx 2 S$.

At the beginning, the inner control loop is designed. Based on the model in (18), the transfer function is obtained for the following initial conditions, which are taken from the stationary state: $x_{10}=1.4 \mathrm{~A}, x_{20}=231.7 \mathrm{~V}, u_{0}=0.69, p_{0}=165.3 \mathrm{~V}$, and PV power $P_{\mathrm{pv}}=1240 \mathrm{~W}$. The other parameters are taken from the experimental test bench: transformer turns ratio $n=8$, input capacitance $C_{\mathrm{pv}}=330 \mu \mathrm{F}$, output capacitance $C_{\mathrm{dc}}=330 \mu \mathrm{F}$, and inductance $L=2.2 \mathrm{mH}$. The transfer function is

$$
\begin{aligned}
& I_{L}=\quad \frac{-+2.42 e^{5}}{s--1.69 e^{7}} \\
& d \quad s^{2} \quad 69.99 s \quad 3.42 e^{6}
\end{aligned}
$$

A PI controller is selected for ensuring zero error in stationary state and to improve the dynamic performance even for the current and voltage control. In order to design the controller, the graphic method using MATLAB tool (rltool) is used for this purpose. 
The first step is to define the parameters settings, the damping ratio $\zeta=0.707$, is selected, because it offers a good compromise between rise time and settling time. Then, the cutoff frequency $f 0=4 \mathrm{kHz}$ is chosen, because the switching frequency is $f_{\mathrm{sw}}=80$ $\mathrm{kHz}$, and with a decade in the following, the response is good enough in terms of settling time $t_{s}=4.3 e_{-}^{-}{ }^{4}$ and overshoot $M_{p}=20 \%$. With these criteria, the current controller is

$$
\begin{array}{ccc}
L & =- & s+7769 \\
C_{I}(s) & 0.09331 . & (20) s
\end{array}
$$

After that, the voltage control loop is design based on the same methodology. In this case, the transfer function is obtained as the relation between the input PV voltage and the current

through the input capacitance. Then, a feed forward is implemented in order to obtain the current through the inductance. The transfer function is

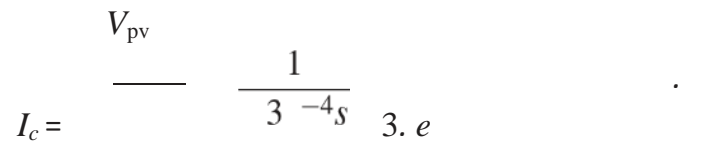

The same criteria are used for the voltage control loop, only considering that its bandwidth is lower than the current control loop. For that reason, the selected cutoff frequency is $f_{0}=71 \mathrm{~Hz}$, which is faster enough for performing the MPPT algorithm. With these criteria, the voltage controller is

$$
\mathrm{pvs}+150 \quad=
$$

$C_{V}(s) 0.10198 . \quad(22)$

$S$

The same methodology is applied for all the PPC configurations. They were not included in detail in this paper due to length limitations, but the most relevant are described for the step-up I, step-up II, and step-down PPCs as follows:

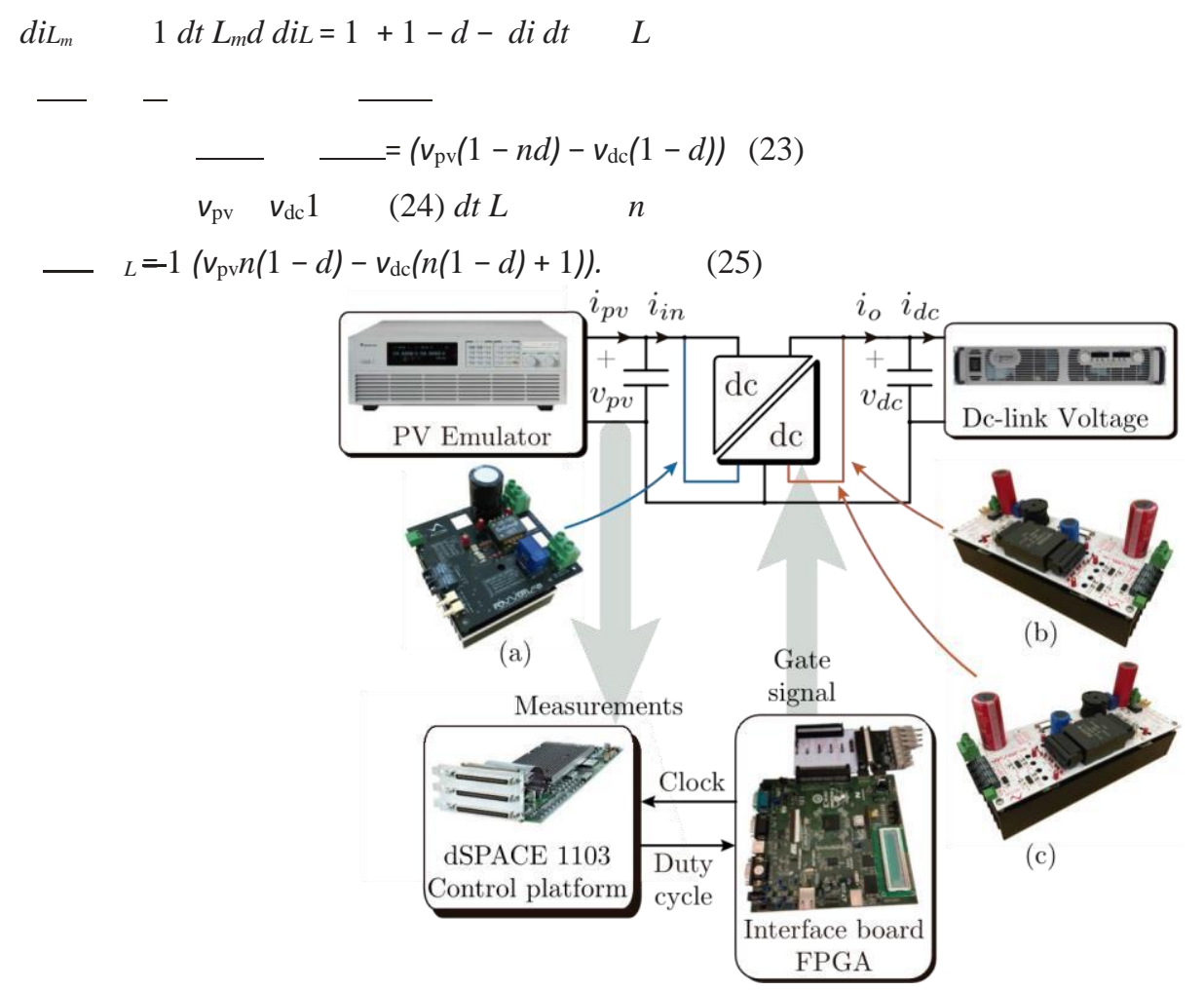

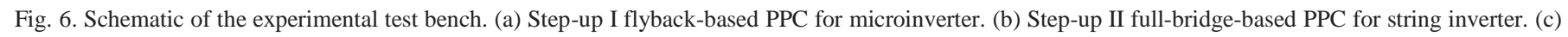
Step-down full-bridge-based PPC for string inverter.

Fig. 5(b) shows the gate signals generation when the flyback topology is used. It also includes the signal for the clamping circuit $\left(S_{c}\right)$. Fig. 5(c) shows the gate signals generation for the full-bridge topology, where the signal for the clamping circuit is also considered. 


\section{EXPERIMENTAL VALIDATION}

The experimental test-bench schematic shown in Fig. 6 is used to validate the different PPC configurations, as well as the theoretical analysis made in Section III. The impact over the partial power ratio and the conversion efficiency are tested operating both in step-up and step-down modes, for which three dc-dc converters prototypes have been built. It is worth noticing that the voltage and power ratings have been scaled from typical applications values to laboratory and components availability. The main reason for this is that the available HF transformers deprive of choosing traditional ratings for power and turns ratio for the corresponding PV applications. Nevertheless, the theoretical analysis and validation still hold, because they are evaluated as power ratios, voltage gains, and duty cycles.

The PV system is emulated with the programmable dc power supply Chroma $62050 \mathrm{H}-600 \mathrm{~S}$, with a solar array simulator (600 $\mathrm{V} / 5 \mathrm{~kW}$ ). The flyback-based PPC is used to validate the step-up I configuration, and two full-bridge-based PPCs are used to validate the step-up II and step-down configurations. The control platform is composed of a dSPACE 1103 controlling the dc-dc converters, an FPGA Spartan-3E generating the high-frequency pulsewidth modulated signals, and an interface board between the dSPACE and the FPGA. The PPC are used to perform the MPPT algorithm controlling the input voltage, and the output voltage is fixed by the dc power supply Agilent N8762A Technologies (600 V/8.5 A) to emulate the grid-tied inverter. The power delivered by the PV system is dissipated in a resistive load. The differential voltage measuring probes

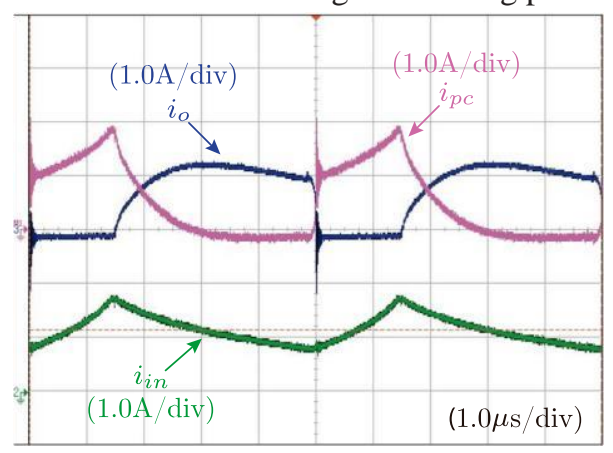

Fig. 7. Current measurements of the Step-up I flyback-based PPC, for microinverter with the clamping circuit and $D=0.28$ and $P$ pv $=35 \mathrm{~W}$. used in the test bench are the Keysight N2790A, $100 \mathrm{MHz}$, and the currents are measured using the Keysight N2783B, 100-MHz probe.

\section{A. Step-Up I Flyback-Based PPC}

Experimental results are provided to validate the configuration shown in Fig. 4(a), with a 100-W test bench. The parameters of the experimental setup are: input capacitance $C_{\mathrm{pv}}=10 \mu \mathrm{F}$, clamping capacitance $C_{c}=5 \mu \mathrm{F}$, output capacitance $C_{\mathrm{dc}}=1000 \mu \mathrm{F}$, transformer turns ratio $n_{1}: n_{2}=4: 4$, and switching frequency $f_{\mathrm{sw}}=200 \mathrm{kHz}$. Similar features as the classic interleaved operation of two converters are obtained working with a single flyback-based PPC topology. More precisely, it operates as the input-parallel output-series (IPOS) configuration, reducing the current ripple at the input of the system and dividing the individual converters power rating.

The waveform shown in Fig. 7 shows one of the advantages of the proposed topology with respect to the traditional IPOS configuration. The measured currents are obtained working with the duty cycle $D=0.28$. In Fig. 7, it can be seen that the resulting input current $i_{\text {in }}$ presents a continuous waveform with reduced ripple. Indeed, the input current $i_{\text {in }}$ is the sum of the current $i_{\mathrm{pc}}$ and $i_{o}$. As those currents are complementary, the resulting current $i_{\text {in }}$ is continuous for any duty cycle if the converter operates under continuous conduction mode and with the transformer turns ratio $n=1$. On the other hand, in the case of the traditional IPOS configuration made with flyback converters, the input current $i_{\text {in }}$ is discontinuous for duty cycles lower than 0.5 .

Due to the presence of parasitic elements in the circuit, combined with the fast switching of the devices, an undesirable ringing effect appears. In order to mitigate this effect, an active clamping circuit is used, which is composed of an additional switch and a capacitor. It mitigates the overvoltages and increases the converter efficiency [24]. The step-up operation is observed in Fig. 8, where the measurements of the voltages are shown working at the rated power. Due to the P\&O MPPT algorithm, it is possible to note the three different voltage-level references. There are MPPT algorithms, which do not produce these voltage oscillations. However, the selection of MPPT is not central to the main contribution of this paper, and the P\&O algorithm is commonly used for this purpose. 


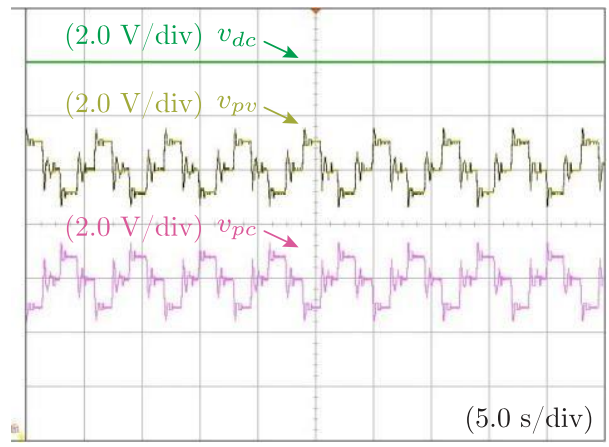

Fig. 8. Voltage measurements of the step-up I flyback-based PPC for microinverter performing the MPPT algorithm with $V \mathrm{pv}=25.1 \mathrm{~V}, V_{\mathrm{pc}}=24.8 \mathrm{~V}, K \mathrm{pr}=43.9 \%$,

and $P$ pv $=105 V \mathrm{dcW} .=49.9 \mathrm{~V}$,

The output voltage $V_{\mathrm{dc}}=49.9 \mathrm{~V}$ is the sum of the input voltage $V_{\mathrm{pv}}=25.1 \mathrm{~V}$ and the partial converter voltage $V_{\mathrm{pc}}=24.8 \mathrm{~V}$. These results represent the mean value of the experimental measurements. Moreover, based on the experimental results, the partial power ratio for the evaluated operation point is $K_{\mathrm{pr}}=43.9 \%$. Due to the length of this paper, efficiency evaluations for this configuration and topology are not included in this paper. Moreover, this PPC configuration and application was already addressed in [11], including the efficiency analysis. Priority is given in this paper to the new configurations presented in this paper, and because the string and multistring applications favor the use of the PPC concept, a higher reduction in the dc-dc converter is achieved.

\section{B. Step-Up II Full-Bridge-Based PPC}

The step-up II configuration is evaluated working with the circuit detailed in Fig. 4(b). It is based on an isolated full-bridge topology, including an active clamping circuit to mitigate the ringing effect. The design is based on the nominal values of the commercial high-frequency Payton Planar transformer $(60 \mathrm{~V} / 30 \mathrm{~A})$ at the primary side, turns ratio $n_{1}: n_{2}=3: 24$, and switching frequency $f_{\mathrm{sw}}=75 \mathrm{kHz}$. Based on these limitations, a $500-\mathrm{W}$ test bench is built. The parameters of the experimental setup are: input capacitance $C_{\mathrm{pv}}=330 \mu \mathrm{F}$, clamping capacitance $C_{c}=47 \mu \mathrm{F}$, output capacitance $C_{\mathrm{dc}}=330 \mu \mathrm{F}$, and inductance $L=270 \mu \mathrm{H}$.

Fig. 9 shows the experimental measurements of the current and voltage when it performs the MPPT algorithm working at $P_{\mathrm{pv}}=$ $1 \mathrm{~kW}$. Note the step-up operation where the output voltage $V_{\mathrm{dc}}=200.4 \mathrm{~V}$ is higher than the input voltage $V_{\mathrm{pv}}=182.2 \mathrm{~V}$. Due to the connection, the partial converter voltage is $V_{\mathrm{pc}}=18.2 \mathrm{~V}$, which is the voltage blocked by the diodes, which is lower than the voltage blocked in an FPC. The input current $I_{\mathrm{pv}}=5.5 \mathrm{~A}$ and the output current

$I_{\mathrm{dc}}=4.5 \mathrm{~A}$ are also shown. These values represent the average value of the waveforms shown in Fig. 9. Moreover, based on the experimental results, the partial power ratio for the evaluated operation point is $K_{\mathrm{pr}}=11.5 \%$. Fig. 10 shows the experimental current measurements of the converter. As it is shown, the input current $I_{\text {in }}=3.4 \mathrm{~A}$ is the sum of the current flowing through the MOSFETS bridge $I_{\mathrm{pc}}=0.7 \mathrm{~A}$ and the

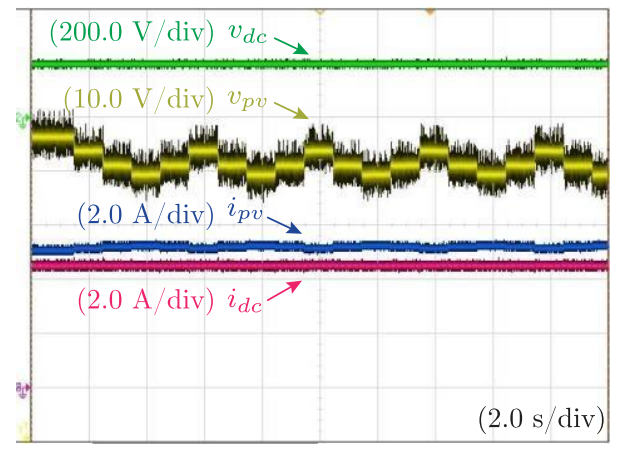

Fig. 9. Voltage and current measurements of the step-up II full-bridge-based

PPC for a string inverter performing the MPPT algorithm with $V \mathrm{pv}=182.2 \mathrm{~V}, I \mathrm{pv}=5.5 \mathrm{~A}, I \mathrm{dc}=4.5 \mathrm{~A}, K \mathrm{pr}=11.5 \%$, and $V \mathrm{dc} P \mathrm{pv}==2001 . \mathrm{kW} .4 \mathrm{~V}$, 


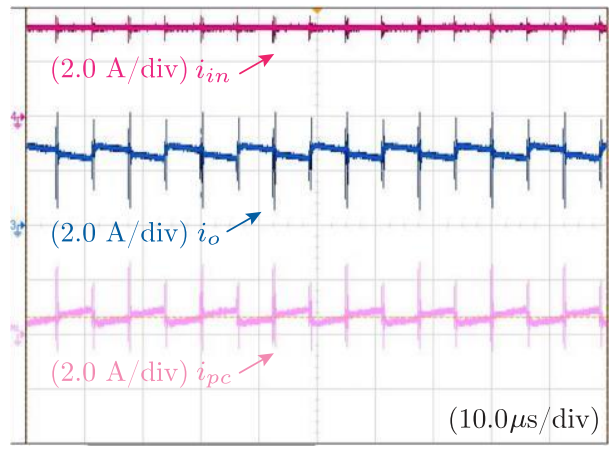

Fig. 10. Current measurements of the step-up II full-bridge-based PPC for a string inverter with $I$ in $=3.4 \mathrm{~A}, I \mathrm{pc}=0.7 \mathrm{~A}$ and $I o=2.7 \mathrm{~A}$.

output current $I_{o}=2.7 \mathrm{~A}$. It means that the semiconductors can be sized for a lower current value than working with an FPC. Moreover, note that the currents $i_{\mathrm{pc}}$ and $i_{o}$ are complementary, resulting in a reduced input current ripple. This effect is obtained because of the connection to create the PPC configuration.

\section{Step-Down Full-Bridge-Based PPC}

The step-down PPC shown in Fig. 2(c) has been implemented with the topology as shown in Fig. 4(c). This PPC bases its stepdown configuration on the same isolated full-bridge topology used for the previous converter, but with the HF transformer with the opposite turns ratio $n_{1}: n_{2}=3: 24$. In addition, the parameters of the experimental setup are: input capacitance $C_{\mathrm{pv}}=330$ $\mu \mathrm{F}$, clamping capacitance $C_{c}=47 \mu \mathrm{F}$, output capacitance $C_{\mathrm{dc}}=330 \mu \mathrm{F}$, and inductance $L=2.2 \mathrm{mH}$.

Fig. 11 shows the experimental measurements of the current and voltage when it performs the MPPT algorithm working at $P_{\mathrm{pv}}$ $=1.24 \mathrm{~kW}$. It is possible to see the step-down operation, with the output voltage $V_{\mathrm{dc}}=165.3 \mathrm{~V}$, which is lower than the input voltage $V_{\mathrm{pv}}=231.7 \mathrm{~V}$. Due to the connection, the partial converter voltage is $V_{\mathrm{pc}}=66.4 \mathrm{~V}$, which is the blocking voltage withstood by the MOSFETS, which is lower than in the case of a traditional FPC. The input current $I_{\mathrm{pv}}=5.3 \mathrm{~A}$ and the output current $I_{\mathrm{dc}}=$

6.7 A are also shown. These results represent the mean value of the waveforms shown in Fig. 11.

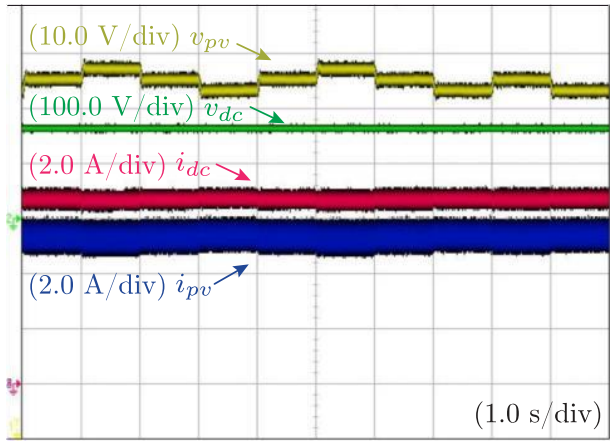

Fig. 11. Voltage and current measurements of the step-down full-bridge-based

PPC for a string inverter performing the MPPT algorithm with $V \mathrm{dc}=165.3 \mathrm{~V}, V \mathrm{pv}=231.7 \mathrm{~V}, I \mathrm{pv}=5.3 \mathrm{~A}, I \mathrm{dc}=6.7 \mathrm{~A}, K \mathrm{pr}=25.2 \%$, and $P \mathrm{pv}=1.24 \mathrm{~kW}$.

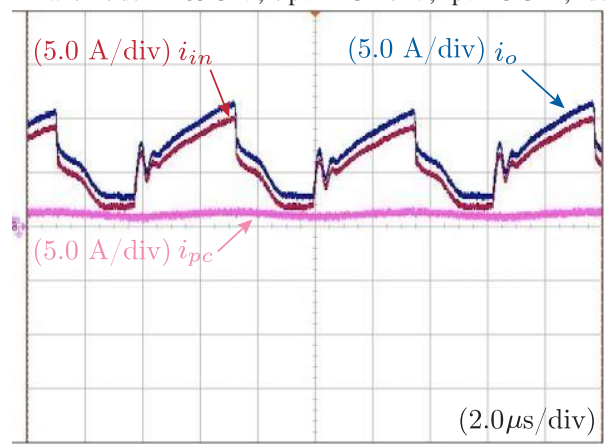

Fig. 12. Current measurements of the step-down full-bridge-based PPC for the string inverter with $I o=6.9 \mathrm{~A}, I \mathrm{pc}=1.1 \mathrm{~A}$, and $I$ in $=5.8 \mathrm{~A}$. 
Moreover, based on the experimental results, the partial power ratio for the evaluated operation point is $K_{\mathrm{pr}}=25.2 \%$. Fig. 12 shows the experimental current measurements of the converter in one operating point. As shown in Fig. 12, the output current $I_{o}=6.9$ A is the sum of the continuous current flowing through the diode bridge $I_{\mathrm{pc}}=1.1 \mathrm{~A}$ and the switched input current $I_{\mathrm{in}}=5.8$ A. It means that the semiconductors can be sized for a lower current value than for an FPC.

\section{Efficiency Analysis}

In order to obtain the experimental efficiency, the power is calculated using the modulated and sampled values of voltage and current (neglecting the high frequency of commutation). The measurements are taken from the whole dc stage (PPC) and the isolated full-bridge dc-dc converter used to make the configuration. These measurements are made for the step-up II and stepdown configurations.

The experimental efficiency waveforms for the step-up II configuration are shown in Fig. 13. The global system efficiency of the dc stage, based on the measurements at the output side $\left(I_{o}, V_{\mathrm{dc}}\right)$ and the input side $\left(I_{\mathrm{pv}}, V_{\mathrm{pv}}\right)$, is obtained under different power and partial power ratios $K_{\mathrm{pr}}$. In the measured range, with the converter operating below $K_{\mathrm{pr}} \leq 10 \%$ of the total power, the global conversion efficiency varies between $98 \%$ and $99 \%$, as shown in Fig. 13(a). On the other hand, the conversion efficiency of the dc-dc converter varies between $70 \%$ and $94 \%$, as shown in Fig. 13(b), where the points

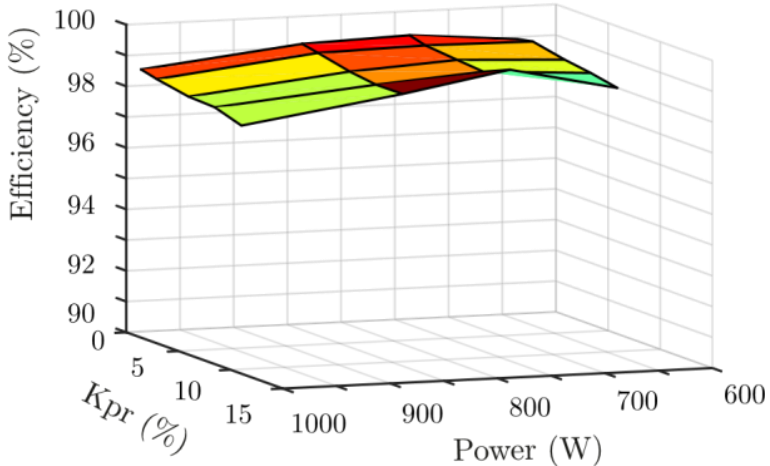

(a)

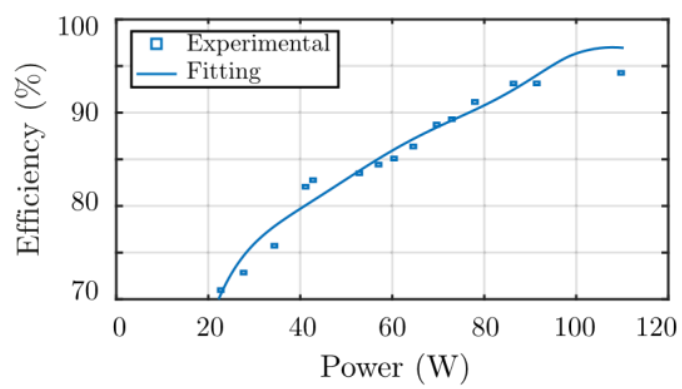

(b)

Fig. 13. Experimental efficiency curves for (a) step-up II full-bridge-based PPC for the string inverter and (b) isolated dc-dc full-bridge converter. TABLE

III EXPERIMENTAL EVALUATION POINTS

\begin{tabular}{lcc}
\hline \hline Parameters & Step-up II & Step-down \\
\hline System Power $(\mathrm{W})$ & 821 & 822 \\
dc-dc Power $(\mathrm{W})$ & 52.5 & 110.1 \\
$K_{p r}(\%)$ & 6.4 & 13.4 \\
PV voltage $(\mathrm{V})$ & 190.4 & 182 \\
Dc-link voltage $(\mathrm{V})$ & 200 & 153 \\
Converter voltage $(\mathrm{V})$ & 9.6 & 47 \\
Global Voltage gain $G_{v}$ & 1.05 & 0.84 \\
Dc-dc Voltage gain $G_{v_{D C}}$ & 20.83 & 0.31 \\
Global efficiency $\eta(\%)$ & 98.5 & 97.5 \\
Dc-dc efficiency $\eta_{d c d c}(\%)$ & 82 & 78.9 \\
\hline \hline
\end{tabular}

obtained from measurements and the corresponding curve fitting are shown. The lower efficiencies can be explained by the fact that the full-bridge converter is operating at a power level much lower to the rated value for which it was designed and the semiconductors are intended. Table III lists the experimental operating point and values for both PPC configurations for one of the experiments that were conducted. As can be seen in this case, the PV system is rated at

$P_{\mathrm{pv}}=821 \mathrm{~W}$, but it is handling $K_{\mathrm{pr}}=6.4 \%$ of the total power. As was explained before, the partial power ratio $K_{\mathrm{pr}}$ is related to the global voltage gain, which is $G_{v}=1.05$. However, due to the series connection, the voltage of the PPC is very small $V_{\mathrm{pc}}=9.6 \mathrm{~V}$, which leads to a high voltage gain for the isolated full-bridge dc-dc converter $G_{v \mathrm{dc}}=20.83$. That is the reason behind the low 
efficiency reached by the full-bridge converter. However, it does not represent a problem for the whole system due to the low power that the converter is processing. Therefore, the power loss related to the dc-dc conversion is $P_{\mathrm{dc}, l}=9.45 \mathrm{~W}$, which represents $1.15 \%$ of the global system losses.

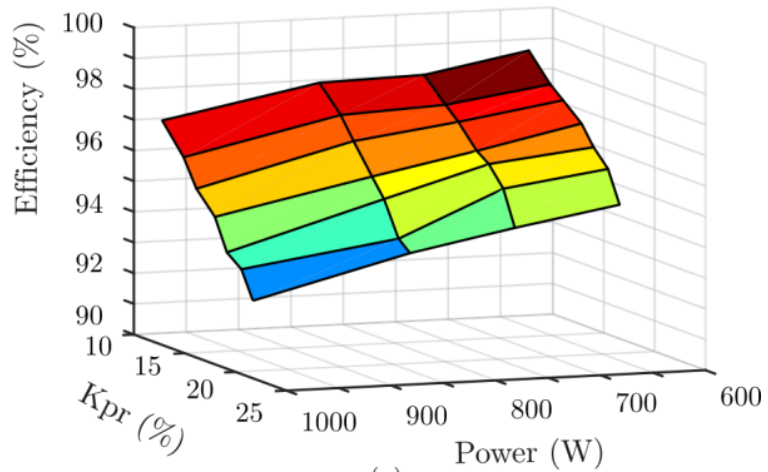

(a)

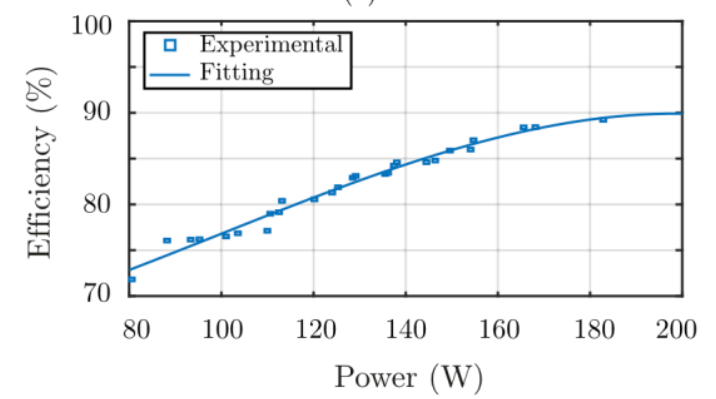

(b)

Fig. 14. Experimental efficiency curves for (a) step-down full-bridge-based PPC for the string inverter. (b) Isolated dc-dc full-bridge converter.

The same analysis is made for the step-down configuration, and the experimental efficiency waveforms are shown in Fig. 14. In the measured range, with the converter operating in the following $K_{\mathrm{pr}} \leq 25 \%$ of the total power, the global conversion efficiency varies between $90 \%$ and 99\%, as shown in Fig. 14(a). On the other hand, the conversion efficiency of the dc-dc converter varies between $72 \%$ and $93 \%$, as shown in Fig. 14(b).

As it can be seen in Table III, the PV system is rated at $P_{\mathrm{pv}}=822 \mathrm{~W}$ and handles only $K_{\mathrm{pr}}=13.4 \%$ of the total power of the system. In that case, the global voltage gain is $G_{v}=0.84$. Nevertheless, due to the series connection, the voltage of the PPC is $V_{\mathrm{pc}}=47 \mathrm{~V}$, which leads to a different voltage gain for the isolated full-bridge dc-dc converter $G_{v d c}=0.31$. This voltage step-down effort impacts the efficiency reached by the full-bridge converter itself, which is relatively low. Therefore, the power loss of the dc-dc conversion is $P_{\mathrm{dc}, l}=23.23 \mathrm{~W}$, which represents $2.83 \%$ of the global system losses.

Laboratory prototypes are not optimized in their design in terms of efficiency for the power rating in which they operate, particularly due to the fact that semiconductors and modules are designed for full-power operation. Consequently, it is expected that for commercial developments, which are optimized in terms of efficiency for a particular power rating, improved efficiencies can be obtained for the dc-dc converter stages, thus further improving the global system efficiency.

\section{E. Losses Distribution}

It is worth noticing that despite being built with the same isolated topology, both the FPC and PPC present differences in terms of operation. The FPC has less circulating energy 


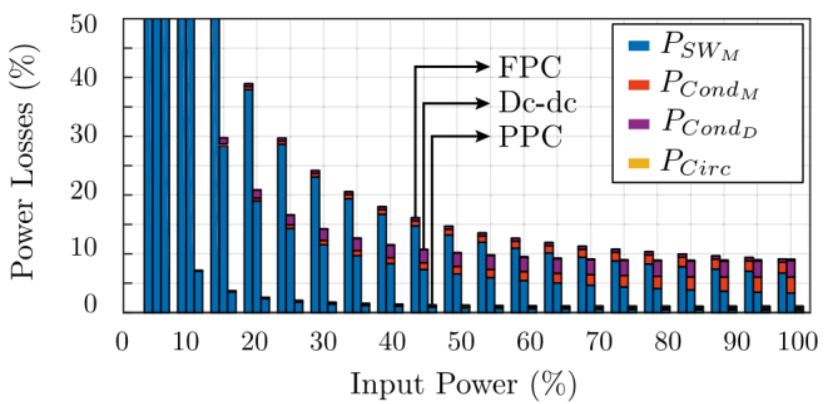

(a)

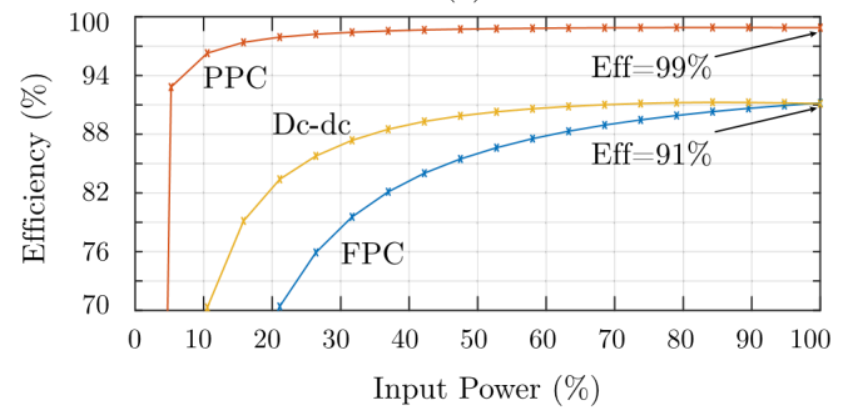

(b)

Fig. 15. Results of the full-bridge FPC, the dc-dc converter used for the PPC, and the PPC used as a dc stage. (a) Power losses distribution. (b) Conversion efficiency.

in the primary of the transformer compared with the dc-dc converter used in the PPC. However, this circulating energy is negligible when considering the efficiency as a system due to the fraction of power handled by the dc-dc converter in the PPC configuration. In order to show this losses distribution, a comparison between the step-up II PPC and the FPC is made, ensuring a similar conversion efficiency at nominal power. This can be seen in Fig. 15(a), where the switching losses $\left(P_{\mathrm{Sw}}\right)$, conduction losses in the MOSFET $\left(P_{\mathrm{Cond} M}\right)$, conduction losses in the diode $\left(P_{\mathrm{Cond} D}\right)$, and circulating energy losses $\left(P_{\mathrm{Circ}}\right)$ are shown for each converter. The dominant losses are related to the switching of the converter. Despite the fact that the proposed dc-dc stage has losses comparable to a full-bridge converter used in the FPC, the PPC configuration has much higher efficiency across the power range of operation as can be seen in Fig. 15(b).

As can be seen in Fig. 15(a), the efficiency of the power conversion is shown in terms of the PV input power variation. The efficiency decreases when the input power also decreases, and it is mainly because of $R d s_{\text {on }}$ and the reverse recovery parameters $\left(t_{\mathrm{rr}}\right.$ and $\left.Q_{\mathrm{rr}}\right)$ of the selected semiconductors. It is traduced in higher switching losses, as shown in Fig. 15(a).

For the PPC analysis, the configuration is analyzed in terms of the total system efficiency and the efficiency of the dc-dc converter. As can be seen in Fig. 15(b), the total system efficiency is higher compared with the traditional FPC, which is explained due to the reduced power handled by the converter (reduced switching losses because the voltage and the current are lower compared with the FPC). Moreover, it is worth noticing that it will have the highest efficiency despite the input power variations, so that switching losses are the most representative, and in the case of PPC, it is the lowest one. As can be seen, the efficiency does not vary significantly for power levels up to $30 \%$ to the rated power, given an almost constant value over a large load.

\section{CONCLUSION}

This paper analyzed different PPC topologies and connection configurations to increase the efficiency of the dc-dc stage in two-stage photovoltaic energy systems. The main feature comes from the fraction of power handled by the power converter, which reduces the total losses in the system. The analyzed topologies and configurations show that the PPC concept is sufficiently flexible to be implemented for step-up dc stages, which are suitable for microinverters and small PV strings, or for step-down dc stages for larger PV strings. The results show that despite the limitation of processing only a fraction of the power, the converter is capable of retaining the MPPT performance. Moreover, the PPC connection adds new benefits, such as input current ripple reduction, which can extend the lifespan of capacitors.

This paper has also shown that the partiality ratio can vary depending on the voltage difference between the PV voltage and the dc-link voltage, the turn ratio of the transformer, and the selected topology. It is also worth mentioning that since the converter efficiency varies depending the power rating, a particular PPC configuration that operates at a lower fraction of power not necessarily translates to higher system efficiency, since it may force the converter to operate at lower power ratings, where it may not be at its most efficient point. This means that it is necessary to optimize the converter design for a particular partiality given by the system parameters, which will even further improve the overall system efficiencies obtained in this paper. 


\section{REFERENCES}

[1] S. Kouro, J. I. Leon, D. Vinnikov, and L. G. Franquelo, "Grid-connected photovoltaic systems: An overview of recent research and emerging PV converter technology," IEEE Ind. Electron. Mag., vol. 9, no. 1, pp. 47-61, Mar. 2015.

[2] M. Kasper, D. Bortis, and J. W. Kolar, "Classification and comparative evaluation of PV panel-integrated DC-DC converter concepts," IEEE Trans. Power Electron., vol. 29, no. 5, pp. 2511-2526, May 2014.

[3] S. Muller, M. Deicke, and R. W. De Doncker, "Doubly fed induction generator systems for wind turbines," IEEE Ind. Appl. Mag., vol. 8, no. 3, pp. 26-33, May/Jun. 2002.

[4] R. M. Button, “An advanced photovoltaic array regulator module,” in Proc. 31st Intersoc. Energy Convers. Eng. Conf. (IECEC), vol. 1, Aug. 1996, pp. 519524.

[5] J. P. Lee, B. D. Min, T. J. Kim, D. W. Yoo, and J. Y. Yoo, "A novel topology for photovoltaic DC/DC full-bridge converter with flat efficiency under wide PV module voltage and load range,” IEEE Trans. Ind. Electron., vol. 55, no. 7, pp. 2655-2663, Jul. 2008.

[6] B.-D. Min, J.-P. Lee, J.-H. Kim, T.-J. Kim, D.-W. Yoo, and E.-H. Song, "A new topology with high efficiency throughout all load range for photovoltaic PCS," IEEE Trans. Ind. Electron., vol. 56, no. 11, pp. 4427-4435, Nov. 2009.

[7] J.-I. Itoh and T. Fujii, "A new approach for high efficiency buck-boost DC/DC converters using series compensation," in Proc. IEEE Power Electron. Specialists Conf., Jun. 2008, pp. 2109-2114.

[8] H. Kim et al., "A high efficiency photovoltaic module integrated converter with the asymmetrical half-bridge flyback converter," Sol. Energy, vol. 84, no. 8, pp. 1376-1381, Aug. 2010. [Online]. Available: http://www.sciencedirect.com/science/article/pii/S0038092X10001787

[9] J. Zhao, K. Yeates, and Y. Han, "Analysis of high efficiency DC/DC converter processing partial input/output power," in Proc. IEEE 14th Workshop Control Modeling Power Electron. (COMPEL), Jun. 2013, pp. 1-8.

[10] M. Harfman-Todorovic et al., "A high efficiency PV micro-inverter with grid support functions," in Proc. IEEE Energy Convers. Congr. Expo. (ECCE), Sep. 2014, pp. 4244-4250.

[11] J. W. Zapata, H. Renaudineau, S. Kouro, M. A. Perez, and T. A. Meynard, "Partial power DC-DC converter for photovoltaic microinverters," in Proc. 42nd Annu. Conf. IEEE Ind. Electron. Soc. (IECON), Oct. 2016, pp. 6740-6745. [12] H. Zhou, J. Zhao, and Y. Han, "PV balancers: Concept, architectures, and realization," IEEE Trans. Power Electron., vol. 30, no. 7, pp. 3479-3487, Jul. 2015.

[13] A. Morrison, J. W. Zapata, S. Kouro, M. A. Perez, T. A. Meynard, and H. Renaudineau, "Partial power DC-DC converter for photovoltaic two-stage string inverters," in Proc. IEEE Energy Convers. Congr. Expo. (ECCE), Sep. 2016, pp. 1-6.

[14] A. D. Marzouk, S. Fournier-Bidoz, J. Yablecki, K. McLean, and O. Trescases, "Analysis of partial power processing distributed MPPT for a PV powered electric aircraft," in Proc. Int. Power Electron. Conf. (IPEC-Hiroshima-ECCE ASIA), May 2014, pp. 3496-3502.

[15] E. Serban, M. Ordonez, and C. Pondiche, "DC-bus voltage range extension in 1500 V photovoltaic inverters," IEEE Trans. Emerg. Sel. Topics Power Electron., vol. 3, no. 4, pp. 901-917, Dec. 2015.

[16] S.-M. Chen, T.-J. Liang, and K.-R. Hu, "Design, analysis, and implementation of solar power optimizer for dc distribution system," IEEE Trans. Power Electron., vol. 28, no. 4, pp. 1764-1772, Apr. 2013.

[17] M. K. Kazimierczuk, Pulse-Width Modulated DC-DC Power Converters. Hoboken, NJ, USA: Wiley, 2008.

[18] T. LaBella, W. Yu, J.-S. Lai, M. Senesky, and D. Anderson, "A bidirectional-switch-based wide-input range high-efficiency isolated resonant converter for photovoltaic applications," IEEE Trans. Power Electron., vol. 29, no. 7, pp. 3473-3484, Jul. 2014.

[19] J. W. Zapata, S. Kouro, G. Carrasco, and H. Renaudineau, "Stepup partial power DC-DC converters for two-stage PV systems with interleaved current performance," Energies, vol. 11, no. 2, p. 357, 2018. [Online]. Available: http://www.mdpi.com/1996-1073/11/2/357

[20] M. Albach, T. Durbaum, and A. Brockmeyer, "Calculating core losses in transformers for arbitrary magnetizing currents a comparison of different approaches," in Proc. 27th Annu. IEEE Power Electron. Specialists Conf. (PESC Rec.), vol. 2, Jun. 1996 , pp. 1463-1468.

[21] H. Cha, L. Chen, R. Ding, Q. Tang, and F. Z. Peng, "An alternative energy recovery clamp circuit for full-bridge PWM converters with wide ranges of input voltage," IEEE Trans. Power Electron., vol. 23, no. 6, pp. 2828-2837, Nov. 2008.

[22] T. Meng, S. Yu, H. Ben, and G. Wei, "A family of multilevel passive clamp circuits with coupled inductor suitable for single-phase isolated full-bridge boost PFC converter," IEEE Trans. Power Electron., vol. 29, no. 8, pp. 4348-4356, Aug. 2014.

[23] N. Femia, G. Petrone, G. Spagnuolo, and M. Vitelli, "Optimization of perturb and observe maximum power point tracking method," IEEE Trans. Power Electron., vol. 20, no. 4, pp. 963-973, Jul. 2005.

[24] M. A. Rezaei, K.-J. Lee, and A. Q. Huang, "A high-efficiency flyback micro-inverter with a new adaptive snubber for photovoltaic applications," IEEE Trans. Power Electron., vol. 31, no. 1, pp. 318-327, Jan. 2016.

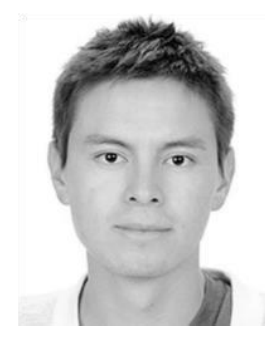

Jaime W. Zapata (S'14-M'17) was born in Latacunga, Ecuador, in 1990. He received the B.Eng. degree in electronics engineering from the Escuela Politecnica Nacional, Quito, Ecuador, in 2013, and the Ph.D. degree in electronics engineering from Universidad Tecnica Federico Santa Maria, Valparaiso, Chile, in 2018.

$\mathrm{He}$ is currently a Post-Doctoral Fellow with the Laboratoire Plasma et Conversion d'Energie, École Nationale Supérieure d'Électrotechnique, d'Électronique, d'Informatique, d'Hydraulique et

des Télécommunications, Institut National Polytechnique de Toulouse, Toulouse, France. His current research interests include power electronics, high-frequency dc-dc converters, multilevel topologies, and photovoltaic energy power conversion systems.

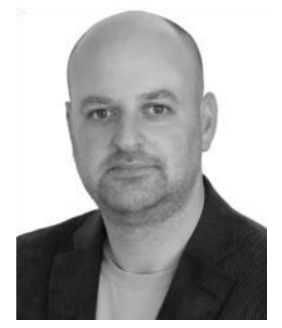

Samir Kouro (S'04-M'08-SM'17) received the M.Sc. and Ph.D. degrees in electronics engineering from Universidad Tecnica Federico Santa Maria (UTFSM), Valparaiso, Chile, in 2004 and 2008, respectively.

In 2007, he joined the Electronics Engineering Department, UTFSM, as a Research Associate, where he currently holds an associate professor position. From 2009 to 2011, he was a Post-Doctoral Fellow with the Department of Electrical and

Computer Engineering, Ryerson University, Toronto, ON, Canada. He has directed seven National Science and Technology Development Fund projects (Fondecyt), is a Founding Member and a Principal Investigator of the Solar Energy Research Center, Chile, one of the national priority areas centers of excellence of Chile, and a Founding Member and a Titular Researcher of the Advanced Center of Electrical and Electronics Engineering, Chile, one of the technology transfers centers of excellence in Chile. He has co-authored one book, seven book chapters, and over 150 refereed journal and conference papers. His current research interests include power electronics, renewable energy conversion systems (photovoltaic and wind), and electromobility.

Dr. Kouro received the 2016 IEEE Industrial Electronics Bimal K. Bose Award for Industrial Electronics Applications in Energy Systems, the 2015 IEEE Industrial Electronics Society J. David Irwin Early Career Award, the 2012 IEEE Power Electronics Society Richard M. Bass Outstanding Young Power Electronics Engineer Award, the 2012 IEEE Industry Applications Magazine First Prize Paper Award, the 2012 IEEE TRANSACTIONS ON INDUSTRIAL ElECTRONICs Best Paper Award, and the 2008 IEEE Industrial Electronics Magazine Best Paper Award. He has served as a Special Session Organizer and the Chair of 12 special sessions in conferences and has been a Guest Editor of five special sections and issues in several IEEE journals. 


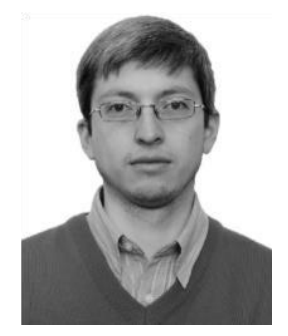

Gonzalo Carrasco was born in Santiago, Chile, in 1984. He received the B.Eng. degree in civil and electronic engineering and the Ph.D. degree from Universidad Tecnica Federico Santa Maria (UTFSM), Valparaiso, Chile, in 2008 and 2014, respectively.

Since 2015, he has been with the Advanced Center for Electrical and Electronic Engineering, UTFSM, as a Research and Development Engineer, where he is involved in circuits design and experimental validation for digital signal processing and power electronics converters. He is also a Lecturer with the Departamento de Electronica, UTFSM.

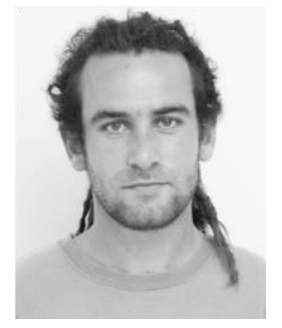

HuguesRenaudineau(M'16) received the Engineering degree in electrical engineering from the Ecole Nationale Superieure d'Electricite et de Mecanique,

Nancy, France, in 2009, and the Ph.D. degree in electrical engineering from the Universite de Lorraine, Nancy, in 2013.

From 2013 to 2015, he was a Post-Doctoral Fellow with the Groupe de Recherche en Electronique et de Nancy, Nancy. From 2015 to 2017, he was a Post-Doctoral Fellow with the Center for Electrical and Electronic Engineering, Universidad Tecnica Federico Santa Maria, Valparaiso, Chile. research interests include photovoltaic systems, power electronics dc-dc and dc-ac converters, and energy storage

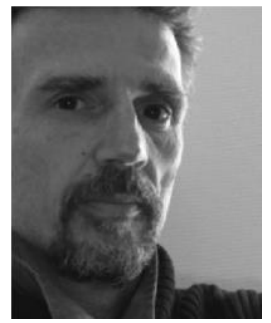

Thierry A. Meynard (M'94-SM'12-F'17) graduated from the Ecole Nationale Superieure d'Electrotechnique, d'Electronique, d'Hydraulique de Toulouse, Toulouse, France, in 1985. He received the Ph.D. degree from the Institut National Polytechnique de Toulouse, Toulouse, in 1988.

He was then an Invited Researcher at the Universite du Quebec a Trois-Rivières, TroisRivières, QC, Canada, in 1989. He joined the Center National de la Recherche Scientifique (CNRS),

France, as a full-time Researcher in 1990, was the Head of the Static Converter Group, France, from 1994 to 2001, and was a parttime Consultant with Cirtem, France, from 2000 to 2016. He is currently the Directeur de Recherches CNRS at the Laboratoire Plasma et Conversion d'Energie, Institut National Polytechnique de Toulouse, and an Associate Director of the national program 3 Dimensional Power Hybrid Integration. In 2016, he co-founded the company Power Design Technologies, Toulouse, which develops

Power Forge, the software for the design of two- and multilevel power converters. Since 2016, he has been a part-time Consultant at PDT, France. He is a co-inventor of several topologies of multilevel converter used by ABB, France, Alstom, France, Cirtem, General Electric, France, and Schneider Electric, France: flying capacitor, stacked multicell, 5LANPC, ac/ac chopper, and xPlexed choppers. His current research interests inlude series and parallel multicell converters, magnetic components, and the development of design tools for power electronics. 